\title{
Apparatus for the Measurement of the Normal Spectral Emissivity in the Infrared
}

\author{
Arthur G. Maki, Ralph Stair, and Russell G. Johnston
}

(December 21, 1959)

\begin{abstract}
Apparatus and methods are described for measuring in the infrared the normal spectral emissivity of metals and coatings or oxides which tightly adhere to metals. Examples of the use of this apparatus are given in measurements of the emissivity of platinum and of oxidized Inconel within the spectral region of 1.5 to 15 microns. Measured values were reproduced to better than 5 percent.
\end{abstract}

\section{Introduction}

The measurement of the spectral emissivity of heated substances may be accomplished by comparing the energy emitted by the substance under study with that emitted by a standard substance for radiation at various wavelengths. For such a standard one usually uses a blackbody, that is, a hollow body provided with a hole for viewing the radiation inside. The inside surface of the blackbody must be maintained at a uniform temperature. The wavelength separation may be accomplished using a double-beam monochromator or a singlebeam monochromator.

The specimen under investigation may be formed into a rod, bar, ribbon, or other shape. Some workers have even formed the specimen into a blackbody. For such a specimen both the inside surface (the blackbody) and the outside surface (the specimen) are observed.

The double-beam monochromator and associated method have certain advantages especially with relation to the elimination of the effects of absorption by carbon dioxide and water vapor, but the optical adjustment is critical as compared with a single-beam instrument. Furthermore through the use of a single set of optics and equal path lengths in the single-beam monochromator the effects of both atmospheric absorption and differential reflectivity in the auxiliary optics are practically eliminated. The apparatus described herein is of the latter type.

The specimen may vary in temperature from point to point depending upon its shape, size, and method of heating. If made into the form of a blackbody the inside temperature may differ from that on the outside. A convenient shape is that of a long thin ribbon heated electrically by contacts at the two ends. The data presented in this paper apply to samples of this type for which the temperature is measured by means of thermocouples in metallic contact with the opposite face from the point of radiant energy measurement.

\section{Apparatus and Method}

This apparatus was set up as shown in figure 1 . The blackbody and sample under investigation were mounted side by side on an optical bench (constructed from a lathe bed and table) so they could be alternately placed at the focal point of the optical system. The auxiliary optics, consisting of a plane and a spherical mirror (65-cm radius of curvature), were mounted rigidly on the monochromator base. The placing of the sample and blackbody aperture alternately at the same position ensured essentially equal light paths and the use of identical optics.

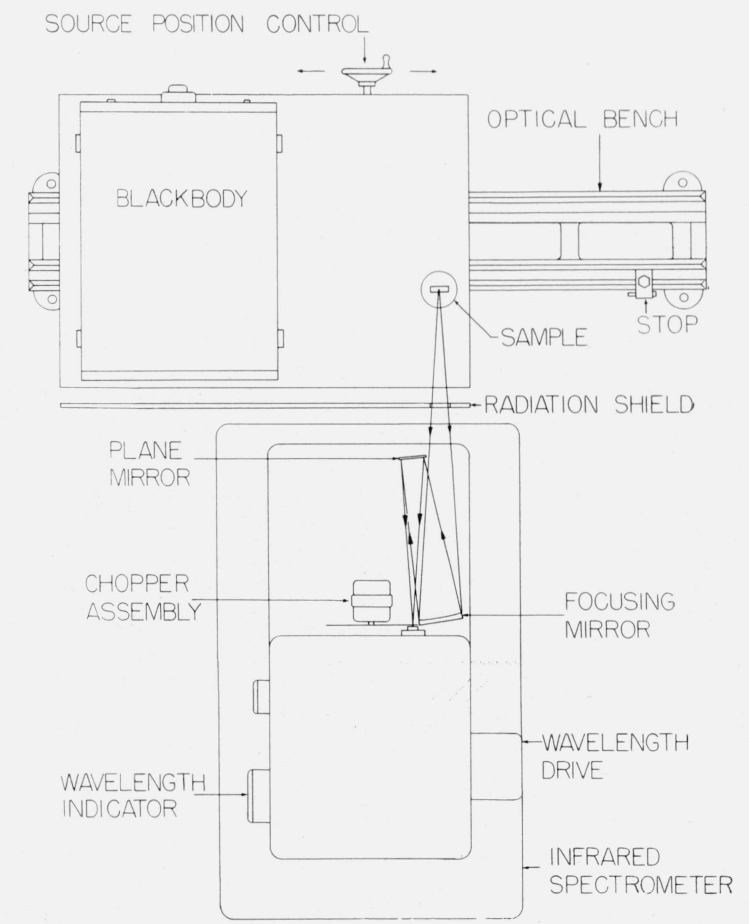

Figure 1. Instrumental setup for the measurement of the normal spectral emissivity of heated substances. 
A single-beam monochromator incorporating a sodium chloride prism and thermocouple was modified to yield the arrangement shown in figure 1 for use in this work. It was calibrated for wavelength in the usual manner by using atmospheric and polystyrene absorption bands. The light beam was chopped at $10 \mathrm{cps}$ and the thermocouple voltage amplified through the use of a ten-cycle thermocouple amplifier giving an approximately linear output.

The linearity of the amplifier was of importance as the emissivity was obtained as the ratio of the measured outputs for the blackbody and specimen, both being maintained at the same temperature. For the high emittance measurements the linearity of the amplifier was checked using filters of known transmission. In the case of the low-emissivity measurements an attenuator switch was used to bring the blackbody and specimen readings within a comparable range. This attenuator was then calibrated by comparing the measured values of the radiant energy from a blackbody at a high temperature with those from the blackbody at a lower temperature. Using the Planck blackbody radiation equation the ratio of the radiation from these two sources was calculated and used to calibrate the amplifier and attenuator.

In this work the wavelength bandwidth (half intensity width) averaged about $0.15 \mu$ although it varied somewhat with the wavelength setting.

The blackbody cavity was constructed of an alloy casting of essentially 80 percent nickel-20 percent chromium (3 in. outside diam. by 6 in. in length, with a wall thickness of about $1 / 2 \mathrm{in}$.). The low reflectivity of this (oxidized) metal coupled with the fact that the aperture was only 0.3 percent of the interior surface area resulted in a blackbody of extremely high effective emissivity (probably 0.999 or above). The high heat capacity of the furnace employed in heating the blackbody gave it a high thermal stability and made manual temperature regulation easy (see fig. 2). The large size of the furnace, the method of heating, and the small furnace aperture used to permit viewing the blackbody yielded a very uniform temperature within the blackbody.

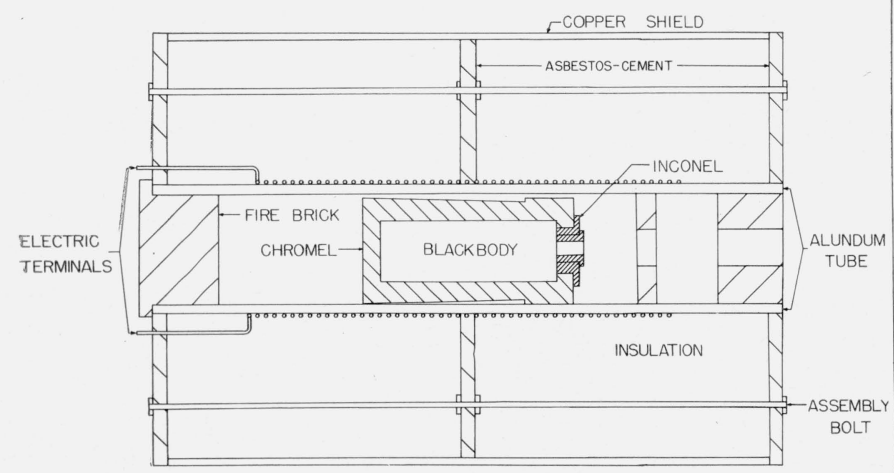

Figure 2. Blackbody and furnace cross section.
The temperature of the blackbody, as well as that of the sample under investigation, was measured through the use of platinum versus platinum-10 percent-rhodium thermocouples. Checks against standard thermocouples indicated that the absolute temperatures of the blackbody recorded herein are correct to within about $\pm 6^{\circ} \mathrm{K}$.

The specimen consisted of a metal strip about $81 / 2$ in. long by $1 / 4$ in. wide and about $1 / 32$ in. thick. The thermocouple used to measure the specimen temperature was welded to the back side of it directly behind the surface area from which the measurements were made. The thermocouple used was of rather small diameter wire $(5$ mils) so that the cooling of the surface which resulted from conduction along the thermocouple wire was quite small. The useful radiating surface area was about $3 / 8$ in. by $1 / 16$ in. and the radiation used was essentially normal to the surface. Observations with an optical pyrometer indicate that the temperature gradient over the observed surface was less than $\sim 4^{\circ} \mathrm{K}$.

The specimen under examination was heated by passing through it an electric current of about 80 amp at $5 \mathrm{v}$. It was clamped rigidly at the two electrodes and held centrally located within a watercooled metal tube, about $1_{1 / 4}^{1 / 4}$ in. inner diameter. Although the inner surface of this tube was highly oxidized, reflection from its inner surface affected the emissivity measurements by about 1 percent. However, its use reduced air currents and added greatly to the stability of the temperature of the sample so that its temperature could be manually held constant within about $\pm 1.5^{\circ} \mathrm{K}$ even at $1,400^{\circ} \mathrm{K}$.

\section{Examples of the Use of This Apparatus}

As examples of the use of this apparatus, the emittances of two very different substances, platinum and oxidized Inconel, were measured. The oxide coating on Inconel has a very high spectral emittance while the surface of platinum being highly reflective has a very low emissivity.

\subsection{Oxidized Inconel}

The Inconel strips were prepared by first cleaning the surface by sandblasting, and then heating in air for $6 \mathrm{hr}$ at a high temperature in order to form an opaque oxide coating.

The spectral emittance of oxidized Inconel is given in table 1 and figure 3 . These data are the average of the values obtained on three separate specimens each of which was run several times at each temperature.

The oxide coating has a very high emissivity as is characteristic of many oxides. The most prominent features of the emissivity curve are two minimums at around 6 and $6.5 \mu$. In this same wavelength region there are two strong absorption maximums for atmospheric water vapor. Although care was exercised to make the pathlengths for blackbody and specimen equal, the atmospheric absorption may be the cause of these minimums. 
TABLE 1. Normal spectral emittance of oxidized Inconel at $1,400^{\circ} \mathrm{K}, 1,050^{\circ} \mathrm{K}$, and $780^{\circ} \mathrm{K}$ from 1.5 to $15 \mu$

\begin{tabular}{|c|c|c|c|}
\hline $\begin{array}{l}\text { Wave- } \\
\text { length }\end{array}$ & $1,400^{\circ} \mathrm{K}$ & $1,050^{\circ} \mathrm{K}$ & $780^{\circ} \mathrm{K}$ \\
\hline $\begin{array}{r}\mu \\
1.5 \\
2.0 \\
2.5 \\
3.0 \\
3.5\end{array}$ & $\begin{array}{r}0.93 \\
.92 \\
.91 \\
.90 \\
.90\end{array}$ & $\begin{array}{r}0.88 \\
.88 \\
.86 \\
.86 \\
.85\end{array}$ & $\begin{array}{r}0.77 \\
.79 \\
.78 \\
.77 \\
.78\end{array}$ \\
\hline $\begin{array}{l}4.0 \\
4.5 \\
5.0 \\
5.5 \\
6.0\end{array}$ & $\begin{array}{l}.90 \\
.90 \\
.90 \\
.89 \\
.86\end{array}$ & $\begin{array}{l}.85 \\
.84 \\
.84 \\
.83 \\
.80\end{array}$ & $\begin{array}{l}.78 \\
.78 \\
.77 \\
.77 \\
.72\end{array}$ \\
\hline $\begin{array}{l}6.5 \\
7.0 \\
7.5 \\
8.0 \\
8.5\end{array}$ & $\begin{array}{l}.86 \\
.88 \\
.90 \\
.91 \\
.91\end{array}$ & $\begin{array}{l}.80 \\
.84 \\
.87 \\
.90 \\
.90\end{array}$ & $\begin{array}{l}.74 \\
.78 \\
.82 \\
.85 \\
.87\end{array}$ \\
\hline $\begin{array}{r}9.0 \\
9.5 \\
10.0 \\
10.5 \\
11.0\end{array}$ & $\begin{array}{l}.92 \\
.92 \\
.92 \\
.92 \\
.92\end{array}$ & $\begin{array}{l}.90 \\
.90 \\
.89 \\
.90 \\
.90\end{array}$ & $\begin{array}{l}.87 \\
.86 \\
.86 \\
.87 \\
.88\end{array}$ \\
\hline $\begin{array}{l}11.5 \\
12.0 \\
12.5 \\
13.0 \\
13.5\end{array}$ & $\begin{array}{l}.93 \\
.94 \\
.95 \\
.95 \\
.96\end{array}$ & $\begin{array}{l}.91 \\
.92 \\
.93 \\
.94 \\
.94\end{array}$ & $\begin{array}{l}.88 \\
.89 \\
.91 \\
.92 \\
.93\end{array}$ \\
\hline $\begin{array}{l}14.0 \\
14.5 \\
15.0\end{array}$ & $\begin{array}{r}.96 \\
.96 \\
.96\end{array}$ & $\begin{array}{r}.94 \\
.94 \\
.94\end{array}$ & $\begin{array}{r}.90 \\
.89 \\
.87\end{array}$ \\
\hline
\end{tabular}

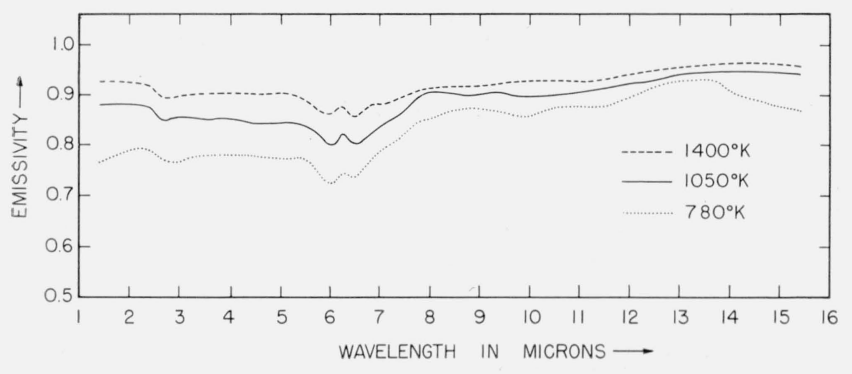

Figure 3. Normal spectral infrared emissivity of oxidized Inconel at selected temperatures.

Figure 3 shows the very distinct trend for the emissivity to increase with temperature. Many nonmetals seem to show very little change in emissivity with temperature. The change which we have observed, however, is attributed to the oxide coating because previous experiments indicate that coatings formed in the manner described are opaque to any radiation from the underlying metal. Moreover, although metals are expected to show such an increase in emissivity with temperature, the emissivity of metals is too low to be a contributing factor.

\subsection{Platinum}

The two platinum strips examined were first annealed by heating to about $1,525^{\circ} \mathrm{K}$. One specimen was held at that temperature for $1 \mathrm{hr}$ while the other was heated for only $10 \mathrm{~min}$. Both specimens, although initially smooth surfaced, acquired a crystalline appearance after the annealing process. This crystalline surface would probably have a slightly different emissivity from a perfectly smooth surface, but infrared radiation, since it has relatively large wavelength, is rather insensitive to small surface irregularities.

The emissivity of the platinum strip is given in table 2 and the results are shown in figure 4 . The low emissivity is characteristic of most metals. This follows from the fact that the reflectivity of metals is very high.

Price [1] ${ }^{1}$ measured the spectral emissivity of platinum at $1,400^{\circ} \mathrm{K}$ over the wavelength range of 0.65 to $4.75 \mu$. Price reported that due to the nonperfect blackbody which he used his emissivity values, if in error, were probably too high. This may account for the fact that our values are everywhere lower than Price's.

TABLE 2. Calculated and observed values of the normal spectral emissivity of platinum at $1,400^{\circ} \mathrm{K}$ from 1.5 to $15 \mu$

\begin{tabular}{|c|c|c|}
\hline $\begin{array}{l}\text { Wave- } \\
\text { length }\end{array}$ & $\begin{array}{l}\text { Calculated } \\
\text { emissivity }\end{array}$ & $\begin{array}{l}\text { Observed } \\
\text { emissivity }\end{array}$ \\
\hline$\mu$ & & \\
\hline 1. 5 & 0. 189 & 0.197 \\
\hline 2. 0 & .165 & .179 \\
\hline 2.5 & .149 & .154 \\
\hline 3. 0 & .137 & .139 \\
\hline 3.5 & .127 & .128 \\
\hline 4. 0 & .119 & .117 \\
\hline 4. 5 & .112 & .108 \\
\hline 5. 0 & .107 & .100 \\
\hline 5.5 & .102 & .094 \\
\hline 6.0 & .098 & .090 \\
\hline 6.5 & .094 & .088 \\
\hline 7. 0 & .091 & .090 \\
\hline 7.5 & .088 & .092 \\
\hline 8.0 & .085 & .093 \\
\hline 8.5 & .083 & .091 \\
\hline 9.0 & .081 & .091 \\
\hline 9.5 & .078 & .090 \\
\hline 10.0 & .077 & .087 \\
\hline 10.5 & .075 & .083 \\
\hline 11.0 & .073 & .080 \\
\hline 11. 5 & .072 & .078 \\
\hline 12. 0 & .070 & .075 \\
\hline 12.5 & .069 & .072 \\
\hline 13. 0 & .067 & .068 \\
\hline 13.5 & .066 & .066 \\
\hline 14.0 & .065 & .064 \\
\hline 14. 5 & .064 & .063 \\
\hline 15.0 & .063 & .065 \\
\hline
\end{tabular}

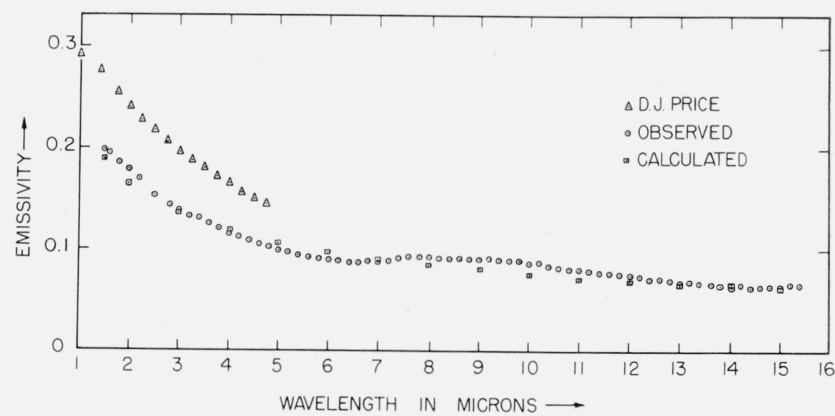

Figure 4. Normal spectral infrared emissivity of commercial grade platinum at $1,400^{\circ} \mathrm{K}$.

Observations by D. J. Price shown by triangles $(\Delta)$; calculated emissivity shown by squares $(\square)$.

${ }^{1}$ Figures in brackets indicate the literature references at the end of this paper. 
In the long wavelength region the emissivity of metals increases with increase in temperature. This fact has been verified for platinum by Hagen and Rubens [2]. Thus our results should be higher than measurements made at lower temperatures. As expected the reflectivity values for platinum at lower temperatures reported by other workers yield emissivity values lower than ours.

The measured spectral emissivity values for platinum may be compared with the theoretical emissivity calculated by using the Drude-Zener relation. This is valid only for metals for which the electrons are perfectly free. According to this relationship [3] the long wavelength spectral emissivity is given by

$$
\epsilon=0.365\left(\frac{\rho}{\lambda}\right)^{\frac{1}{2}}-0.0464 \frac{\rho}{\lambda} .
$$

Here $\rho$ is the electric resistivity of the metal in ohm centimeters and $\lambda$ is the wavelength in centimeters. Table 2 and figure 4 include the theoretical emissivities calculated using this equation and the resistivity value $46.52 \mu \mathrm{ohm} \mathrm{cm}$ measured at $1,400^{\circ}$ $\mathrm{K}$ by Wm. F. Roeser [4].

At long wavelengths the measured emissivity is in excellent agreement with the theoretical values. There is, however, an unexpected rise in the observed values around 8,9 , and $10 \mu$. This may be due to very small amounts of impurities on the surface of the metal. The deviation at shorter wavelengths may be partially due to the fact that the theoretical curve is expected to apply only to the long wavelength region.

\section{Conclusion}

The apparatus described in this paper may be used to measure the emissivity of metallic substances or substances capable of forming tightly adhering coatings on metals to within about \pm 3 percent for substances with a high emittance and to about \pm 5 percent (of measured value) for substances with a low emittance. For highly emissive substances the temperature measurement is probably the principal source of error while for low-emittance specimens the amplifier stability becomes a major source of error. The reproducibility of the results has been found to be very good. It was checked by making repeated measurements on the same specimen and on different specimens of the same material. In addition a different operator was used to check some of the work.

One could also measure the emissivity by changing the blackbody temperature so as to equate the radiation of sample and blackbody. The principal source of error would then be due to the temperature measurement for all emissivity values. A big disadvantage of this procedure is the slowness of making measurements due to the large thermal inertia of the blackbody.

In conclusion the authors express their gratitude to Wm. F. Roeser of the Building Technology Division for helpful suggestions; also to Fred Shorten for assistance in taking some of the observations.

\section{References}

[1] D. J. Price, Proc. Phys. Soc. (London) 59, 118 (1947).

[2] E. Hagen and H. Rubens, Ann. Physik 11, 873 (1909)

[3] Max Jakob, Heat transfer, vol. I (John Wiley and Sons, Inc., New York, N.Y.).

[4] Temperature; its measurement and control in science and industry, p. 1312 (Reinhold Publishing Corp., New York, N.Y.).

Washington, D.C.

(Paper 64C2-29) 